\title{
CHALLENGES AND OPPORTUNITIES IN CLINICAL ETHICS WITH THE IMPLEMENTATION OF KOREA'S END-OF-LIFE ACT
}

\author{
Claire Junga Kim ${ }^{1}$
}

\begin{abstract}
This paper examines the possible impacts of the Act on Decisions on Life-Sustaining Treatment for Patients in Hospice and Palliative Care or at the End of Life in Korea (Korea's end-of-life act), legislated in 2016, on the development of hospital ethics committees and clinical ethics consultation services in South Korea. Clinical ethics in Korea has not made much progress in comparison to other subdisciplines of biomedical ethics. While the enactment of this law may give rise to beneficial clinical ethics services, it is possible that customary practices and traditional authorities in Korean society will come into conflict with the norms of clinical ethics. This paper examines how the three main agents of Korean society-family, government, and medical professionals_-may clash with end-of-life stage norms in clinical ethics, thus posing obstacles to the development of hospital committees and consultation services. A brief outline of what lies ahead for the progress of clinical ethics practice is explored.
\end{abstract}

Keywords: Clinical ethics, Hospital ethics committee, Ethics consultation, Life-sustaining treatment, End-of-life care, Self-determination

\section{Desafíos y oportunidades en ética clínica con la implementación de la Ley de fin de vida de Corea}

Resumen: Este documento examina los posibles impactos de la Ley de decisiones sobre el tratamiento de soporte vital para pacientes en hospicios y cuidados paliativos, o al final de la vida en Corea (Ley de Corea del Final de la Vida), legislada en 2016, sobre el desarrollo de comités de ética hospitalaria y servicios de consulta de ética clínica en Corea del Sur. La ética clínica en Corea no ha avanzado mucho en comparación con otras subdisciplinas de la ética biomédica. Si bien la promulgación de esta ley puede dar lugar a servicios de ética clínica beneficiosos, es posible que las prácticas tradicionales y las autoridades tradicionales en la sociedad coreana entren en conflicto con las normas de ética clínica. Este documento examina cómo los tres agentes principales de la sociedad coreana — familia, gobierno y profesionales médicos — pueden chocar con las normas de ética clínica al final de la vida, lo que plantea obstáculos para el desarrollo de comités hospitalarios y servicios de consulta. Se explora un breve resumen de lo que queda por delante para el progreso de la práctica de la ética clínica.

Palabras clave: ética clínica, comité de ética del hospital, consulta de ética, tratamiento de soporte vital, atención al final de la vida, autodeterminación

\section{Desafios e oportunidades em ética clínica com a implementaçáo do Ato de Fim-da-Vida na Córeia}

Resumo: Este artigo examina os possíveis impactos que o Ato sobre Decisões Relacionadas a Tratamento de Manutençâo da Vida para Pacientes em Casas de Idosos e de Cuidados Paliativos ou ao Fim da Vida na Coréia (ato de fim da vida da Coréia), aprovado pelo legislativo em 2016, sobre o desenvolvimento de comitês de ética de hospitais e serviços de consulta sobre ética clínica na Coréia do Sul. Ética clínica na Coréia não sofreu muito progresso em comparação com outras subdisciplinas da ética biomédica. Enquanto a promulgação desta lei pode dar origem a serviços de ética clínica proveitosos, é possível que práticas usuais e autoridades tradicionais na sociedade coreana entrarão em conflito com as normas da ética clínica. Este artigo examina como os três principais agentes da sociedade coreana - família, governo e profissionais médicos - podem se chocar com normas de estágios de fim da vida em ética clínica, colocando assim obstáculos para o desenvolvimento de comitês hospitalares e serviços de consulta. Um breve esboço do que vem pela frente para o progresso da prática de ética clínica é explorado.

Palavras chave: ética clínica, comitê de ética hospitalar, consulta ética, tratamento de manutenção da vida, cuidados de fim da vida, autodeterminação

\footnotetext{
${ }^{1}$ Department of Medical Education, Ewha Womans University College of Medicine. Seoul, Korea Correspondence: clairejungakim@gmail.com
} 


\section{Introduction}

In 2016, the Act on Decisions on Life-Sustaining Treatment for Patients in Hospice and Palliative Care or at the End of Life (hereafter the Act)(1) was signed. The Act is a law concerning the withholding and withdrawing of life-sustaining treatments for patients at the end of life. It serves as an opportunity to promote the practice of clinical ethics in the form of hospital ethics committees or clinical ethics consultation services. This is because the law clearly recognizes patients' rights to self-determination concerning life-sustaining treatment, it mandates the establishment of institutions for clinical ethics practice, and therefore, it facilitates public discussion and policy development related to clinical ethics issues. To date, education and research aspects of biomedical ethics have made great progress in Korea, as has the practice of research ethics. Nevertheless, the practice of clinical ethics in hospitals has not been well developed to date, and services to jointly discuss and address ethical issues are still lacking. Therefore, it is meaningful to investigate whether enactment and enforcement of the Act have the potential to lead to successful implementation of clinical ethics committees and consultation services. This paper attempts to examine the possibility of the practice of clinical ethics flourishing in Korea and to identify potential obstacles that may prevent such success. Potential obstacles include the risks of customary practices in Korea conflicting with biomedical ethics, which is an imported discipline. In particular, this paper investigates how family, government, and medical professionals - three tenets of authority in Korean society - may emerge as obstacles to the practice of clinical ethics.

\section{Development of Biomedical Ethics in Korea}

The groundwork for the practice of clinical ethics in Korea has been laid with the enactment and enforcement of the Act. This paper follows the definition of clinical ethics according to Singer, Pelleggrino, and Siegler, as having a goal "to improve the quality of patient care by identifying, analyzing, and attempting to resolve the ethical problems that arise in practice(2)." Therefore, as a subdiscipline of biomedical ethics, clinical ethics comprises research, education, and practice di- rectly related to patient care. The purpose of this paper is to explore challenges and opportunities as the establishment of ethics committees and consultation services-common types of clinical ethics in practice-emerges in Korea.

Similar to the history of modern biomedical ethics in many other countries, the practice of biomedical ethics in Korea has developed rapidly over a short period of time. As for education aspects of biomedical ethics, although the field was initially introduced in few medical schools for future doctors in the late 1980s(3), it has now become part of the common curricula in Korean medical schools, and is covered in medical licensing exams for doctors. Graduate schools are also providing relevant programs. Research aspects of biomedical ethics began to emerge with the foundation of the Korean Society for Medical Ethics in 1997(4) and the Korean Bioethics Association in the following year(5). These have led meaningful academic discussions by way of published discourse in academic journals. The Korea National Institute for Bioethics Policy(6), along with many medical schools that conduct biomedical ethics research, publish frequently on the topic in their journals and actively participate in academic discussions. The practice of biomedical ethics has been positively impacted by the abovementioned progress made in the academic world, which has led to the establishment of institutions and laws related to bioethics. In 2005, South Korea's Bioethics and Safety Act was legislated(7), a bill on the rights of human research subjects, on genetics, and on embryo-related research. A department was established at the Ministry of Health and Welfare to address bioethics-related issues. The National Bioethics Committee(8) was established together with the Korea National Institute for Bioethics Policy, a foundation to support the committee. Additional to all these initiatives, many institutions and laws related to new bioethics issues, including clinical trials for medicines and medical devices, have been introduced. Needless to say, it is the bioethics scholars who have made significant contributions to this dimension of progress in biomedical ethics. Among many areas of bioethics in practice, rapid progress has been made in the field of research ethics in particular. With institutional review boards (IRBs) established in 
the majority of hospitals and universities, research ethics education has been provided to researchers, and a consensus in research ethics has been built through peer reviews. The number of trained assistant staff, such as assistant administrators, has increased as well. Nevertheless, the practice of clinical ethics has shown insignificant progress in comparison to accomplishments in research and education aspects of biomedical ethics, and likewise, insufficient progress in comparison to accomplishments in the practice of research ethics, which is a subdiscipline of biomedical ethics.

Among many activities that deal with ethical issues related to bedside patient care, this paper is particularly concerned with the establishment of ethics committees and consultation services, the role of which is to address and discuss pertinent issues and suggest the best possible solutions to problems. This is not to say that the goal of an ethics committee or consultation service in dealing with such ethical issues is merely to seek resolution, thereby ignoring the process of identifying and analyzing the problems. Nor do we disregard the possibility of having independent healthcare professionals who are sufficiently competent to identify and appropriately deal with any ethical issues they may face, even in the absence of formalized institutions or processes such as a committee or consultation service. Nevertheless, it is safe to presume that when clinical ethics consultation services are standardized across hospitals, as long as the usefulness of the practice is undeniable, a culture will be fostered among healthcare professionals wherein clinical ethics are valued and ethics-related issues are addressed with systematic efforts. Viewed in this light, the practice of clinical ethics has yet to reach an advanced stage in Korea. Ethics-based services provided by individual consultants are few, and ethics committees are installed in hospitals only nominally. Until a few years ago, the number of annual meetings held by hospital ethics committees in hospitals averaged 2(9), which is a small number. Many of the committees were paper committees, operating in name only. Under these circumstances, Korea's end-of-life act was legislated, mandating that hospitals that provide life-sustaining treatments must install ethics committees, known as healthcare institution ethics committees according to the law. Therefore, the Act paved the way for clinical ethics, once limited to areas of research and education, to be extended to real-world practices in healthcare.

\section{Korea's End-of-life Act and Further Opportu- nities}

The Act, legislated in February 2016, covers hospice and palliative care, as well as decisions on life-sustaining treatment. Articles on hospice and palliative care were enforced 18 months after the enactment of the law and articles on decisions on life-sustaining treatment came into effect two years after enactment. Hospice and palliative care-related content in the Act mainly serves to promote related fields, while content on decisions about life-sustaining treatment in the law explicates the extent of patients' rights to forego life-sustaining treatment, the means thereof, and the obligations of medical professionals, medical institutions, and the nation to help patients realize their rights. Hence, the Act, especially the articles pertaining to decisions on life-sustaining treatment, is closely linked to clinical ethics. Legal content including an advance statement on life-sustaining treatment and a life-sustaining treatment plan, each more or less corresponding to practices of advance directives and Physician Orders for Life-Sustaining Treatment (POLST) in the US, is provided in the Act, whereby patients' stated intentions to withhold or withdraw life-sustaining treatments are indicated. However, advance statements on life-sustaining treatment are different from advance directives insofar as advance statements exclude the element of durable power of attorney. In addition, legal documents in the Act only allow patients to opt out of life-sustaining treatments that are designated by the law, as opposed to allowing them to provide value history or to indicate their wishes in an open-ended blank space. Presently, the term "life-sustaining treatment" is defined in the Act as a "medical treatment by cardiopulmonary resuscitation, hemodialysis, administering anticancer drugs, mechanical ventilation and any other treatment prescribed by Presidential Decree to a patient at the end of life, which merely extend the duration of the end-of-life process without curative effect(1)." The definition of "life-sustaining treatment" which patients can opt out of accord- 
ing to the Act is highly rigid, specifically stating the purpose and nature of treatment, as well as treatment type and timing of treatment, setting a time frame as the end-of life process. The term "end-of-life process" is also strictly defined as a stage closer to imminent death, distinct from the "terminal stage" of a patient's life, which could last months before the patient's death. From a logical point of view, the Act is interpreted to mean that life-sustaining treatments to extend the duration of life during the terminal stage must be maintained, and that such treatments may only be withheld or withdrawn from patients when they enter the end-of-life process. Moreover, in cases of artificial nutrition, hydration, and simple oxygen, these treatments may not be withheld or withdrawn at any time because the Act recognizes patients' rights to self-determination to a limited extent only. Nonetheless, despite the Act's limitations, it is clear that the law does provide a landmark opportunity for clinical ethics in Korea, particularly for the practice of clinical ethics.

First, the Act is the inaugural law in Korea stating the rights of patients to self-determination in decisions on life-sustaining treatment, despite limiting the scope of life-sustaining treatment to patients at the end-of-life only. Previous court rulings had established that the right to making decisions on medical treatment belonged to the patient alone, and not anyone else $(10,11)$. In addition, other rulings have indicated that decisions on life-sustaining treatment for incompetent patients could be made based on wishes previously stated by the patient before he or she had become incompetent (12). Before enforcement of the Act, however, no law existed to declare the extent of patients' rights to self-determination, to specify legal documents for patients to realize their rights, and to prescribe the obligations of medical professionals to carry out the withholding or withdrawal of life-sustaining treatments. There is no doubt that the Act clearly enhances people's recognition of their rights around life-sustaining treatments. In addition, insofar as the Act compels medical professionals to understand and agree to the rights of patients to self-determination at the end of life, it can be said that the law has caused medical professionals to adopt an important premise for the practice of clinical ethics.
Second, the Act requires establishment of an official body for the practice of clinical ethics. Article 14 says that "a medical institution that intends to perform the services concerning [the] withdrawing and withholding of life-sustaining treatment shall establish a healthcare institution ethics committee(1)." Healthcare institution ethics committees are required by law to perform activities such as deliberation, counseling, and education, thereby making them analogous to hospital ethics committees (HECs), with an exclusive focus on cases related to life-sustaining treatment. As of March 2019, 174 medical institutions have installed healthcare institution ethics committees(13), a trend that is similar to what happened in the history of Korea's research ethics field. When the Bioethics and Safety Act(7) required institutions to establish institutional review boards (IRBs), it prompted hospitals, and subsequently universities, to secure relevant services and human resources. Certainly the rapid progress in the field of research ethics was partly attributable to legal requirements from the Bioethics and Safety Act. Thus we can expect that explicit requirements in the Act concerning the establishment of healthcare institution ethics committees are likely to lead to identifying, analyzing, and resolving ethical issues related to life-sustaining treatments. In turn, these advancements will stand to serve as a foundation for dealing with a greater scope of ethical issues that arise in bedside patient care, not being limited to ethical issues around life-sustaining treatment.

Third, by strengthening people's recognition of their rights to self-determination at the end of life and accelerating the establishment of healthcare institution ethics committees, the Act has generated discourse and publicized clinical ethics issues, and has facilitated relevant policy development, including amendment of the Act. More discussion than ever before has occurred concerning people's end-of-life decisions. Not only the implications and effectiveness of the Act, but also limitations and shortcomings in the application of the law have been reflected upon and analyzed from both within and outside of the medical profession. This type of engagement allows tacit assumptions, which had been previously accepted without questioning, to be tested and further 
challenged. Such assumptions include people's definitions of what is a good death, of maintaining dignity at the end-of-life, the role of government, medical professionals, and families, and patients' rights. Practices that were once carried out without any special consideration, such as treating patients at terminal stages according to the wishes of patients' families without informing patients of their health status, have now been brought to light to be scrutinized in terms of legality and ethicality.

Consequently, will enforcement of the Act cause the practice of clinical ethics to thrive in Korea? Just as the practice of research ethics has become an everyday protocol with the institutionalization of IRBs, does the practice of clinical ethics consultation have the potential to take root in the daily lives of patients and their families? What is more, does the future workforce in the practice of clinical ethics have the potential to be professionalized, as in the case of the United States? In the US, certification programs for ethics consultation services are now being established by academic society(14). The professionalization of clinical ethics practice in the US took place within thirty years following the enactment of the Patient Self Determination Act in 1990(15), which officialized patients' rights to self-determination in healthcare decisions. In 1991, the Joint Commission on Accreditation of Healthcare Organizations called for a "mechanism" for "the consideration of ethical issues arising in the care of patients(16)." During the preparatory stage for enforcement of the Act, and ongoing in the early stages of enforcement, scholars of biomedical ethics are working to sketch out prospects, as well as determine possible leading consultation types of clinical ethics practice in Korea, while also expressing an urgent need for manpower and resources in the field. There are mixed outlooks, some rosy and some gloomy. Acknowledging that the author holds a biased view, not free from the influence of personal inclination and social position, this paper aims to analyze in the most objective way possible the impact of the new set of circumstances caused by the Act on the practice of clinical ethics in Korea. Insofar as the possible positive outcomes of the Act have already been explored, we turn now to limitations in terms of what the Act can realistically do.

\section{Challenges in the Future of Clinical Ethics}

When predicting the impact of the Act, it must be considered that biomedical ethics is an "imported discipline" in Korea. While the history of biomedical ethics traces back to the long tradition of healing practices or the history of the healing profession itself, the modern meaning of biomedical ethics emerged in the late 1960s in the US, thereafter becoming formalized as an academic field (17). Accordingly, in many countries, including Korea, biomedical ethics is not an indigenous discipline, but rather an imported one in which already advanced theories are introduced in academic settings and taught to succeeding generations. This implies that the nature of the tenets of an imported discipline, in terms of its conceptions of individuals and society, may differ from those of a native culture and native institutions. For instance, it has been continuously pointed out that the conception of individualistic autonomy is a central premise of Western biomedical ethics, but is not central in non-Western civilizations $(18,19,20)$. As issues arising in clinical ethics are closely intertwined with our real lives, a clash between aspects of the imported discipline and our customary practices will inevitably emerge. Situations involving clinical ethical issues are very specific-indeed, inseparable-to human lives insofar as the discipline deals with patient care wherein sick people are being looked after by others. Therefore, not surprisingly, these situations intersect with certain customary practices, regulations, and power structures of Korean society. Conversely, there are also extensive customary practices, regulations, and power structures specific to medical practices in Korea, which recur in our daily lives as second nature, all of them inextricably entwined with historic and sociopolitical factors. For instance, treatment decisions for elderly patients are frequently affected by different sets of roles and the status of patients' adult-age children based on gender. Also, doctors' tendencies toward medical overtreatment can be attributed to the existence of criminal status for the assisting of suicide under Korea's criminal law. Therefore, these tacit norms specific to Korea may collide with the practice of clinical ethics insofar as clinical ethics, among all the other subdisci- 
plines of biomedical ethics, is most closely related to the ways that people live their lives. Indeed, such a fundamental collision could pose challenges for clinical ethics in practice.

Nevertheless, in consideration of how research ethics has successfully been put into practice in Korea over the past ten years, one might assume that clinical ethics would simply replicate that success. This, however, is a highly optimistic view. It cannot be assumed that the successful establishment of IRB systems in hospitals and universities ensures the successful establishment of hospital ethics committees or healthcare institution ethics committees in the future. This is because the history of patient care goes far beyond the history of clinical trials or human-subject research. Undoubtedly, patient care is more closely linked to our lives than research. In fact, patient care activities existed most extensively long before the framework of biomedical ethics came along. Therefore, certain customary practices, regulations, and power structures are already deeply rooted within such activities. As a result, norms in clinical ethics are much harder to standardize internationally than norms in research ethics. In other words, the likelihood of a clash between systemized norms in imported disciplines and existing norms in a society is much greater in the field of clinical ethics than in the field of research ethics. To illustrate the challenges facing successful implementation of the practice of clinical ethics in Korea, this paper further investigates how the three main agents of unquestioned authority in Korean medicine stand to clash with the norms of clinical ethics as widely accepted in preexisting discussions of bioethics. The authority of these three main agents- family, government, and medical professionals — often clashes with a concept of democracy, which is a valued prerequisite of biomedical ethics, an imported discipline. In fact, the granting of unwavering authority to three agents is not necessarily the result of an extensive process of validation, nor is it the most appropriate arrangement for addressing the challenges that occur in the practice of medicine. Therefore, not only does the status quo need not be blindly accepted, its acceptance based on tradition alone may not be justified. Nonetheless, in order for biomedical ethics to flourish, and for the practice of clinical ethics to be established in Korea, an honest examination of the current state of affairs is needed and endeavors toward required changes are imperative. This paper does not intend to highlight a pessimistic scenario wherein the future practice of clinical ethics fails in Korea. Rather, it intends to lay the groundwork for further discussion based on accurate recognition of possible challenges, thereby potentially resulting in a new social consensus through research and education, ultimately enabling the benefits of clinical ethics practice for patients and their families. Illustrated below are the ways that the traditional agents of authority may clash with the norms of clinical ethics, particularly in end-of-life care situations, which is a topic of wide discussion since implementation of the Act.

\section{(1) Family}

In contrast to Western countries, families play a crucial role in deciding upon patient treatments in many East Asian countries, including Korea. Decisions about treatments are often made by family members on behalf of competent patients, and doctors are often asked not to disclose diagnoses to patients in terminal stages of illness, due to families' concerns that patients will be psychologically impacted in negative ways. Theoretical efforts have been made to justify such customary practices, suggesting the concept of "familial autonomy" in place of the concept of Western individual autonomy (20). Yet the fact that families hold significant power in deciding upon patient treatments in East Asian countries does not simultaneously nullify the need for, or invalidate the concept of individual autonomy. This is because East Asian countries, including Korea, are now swiftly shifting toward large-scale recognition of individuals' rights. Moreover, imposing a single dominant tenet of social ideology stands to undermine the quality care for diverse patients. Indeed, many patients, especially seniors, have indicated that they would like to be informed of their own diagnoses directly from doctors(21). Therefore, intentionally not informing patients of the status of their own health based on the request of patients' families and/or communicating only with patients' families about decisions on treatments are behaviors that are becoming increasingly unacceptable. 
Another possible factor that may pose a challenge to nascent clinical ethics practice due to implementation of the Act is an unwelcoming attitude of families towards HECs or consultation services. It has long been accepted that decisions on patient treatments are matters that fall strictly under the category of "family issues" or personal business, precluding the intervention of any outsider. Such categorization, however, may eliminate any possibility for medical experts, HECs, and consultants to step into the decision-making process in order to best serve the interests of patients who have become incompetent. If families are seen as "single units" for the making of certain decisions for patients at the end of life instead of a composition of individual family members, opinions of individual family members as well as their existence will naturally be disregarded. Subsequently, the practice of clinical ethics will struggle to step into the decision-making process, as clinical ethics practice aims to facilitate communication between members of the family and help them make the best decisions based on medical facts. Below is an example of how a specific article of the Act, when applied to a real situation, may raise such issues. Article 18 of the Act(1) states that the decision to withdraw or withhold life-sustaining treatment can be made by the patient's family on behalf of the patient, if all members of the patient's family reach unanimous agreement. However, the article does not indicate what matters family members must unanimously agree upon, and by what criteria agreement must be reached. In bioethics literature, the widely accepted criterion is "the best interest of a patient" in cases wherein it is impossible to verify a patient's intentions for their own life-sustaining treatment $(22,23)$. Thus, as a part of clinical ethics practice, an HEC or individual consultants could elucidate such criterion for patients' families, thereby facilitating pertinent discussions among family members. However, if clinical ethics practitioners are blocked outright from decision-making processes due to patient treatment being regarded as a "family issue," then the experts will not be able to provide the necessary help to patients and their families.

\section{(2) Government}

The government of South Korea takes a paternalistic approach to matters of people's lives and deaths. Aiding and abetting suicide is regarded as a criminal offense(24). In the context of healthcare, many medical professionals fear accusations of aiding and abetting suicide or aiding a murder due to the withdrawal of life-sustaining treatments according to patients' will insofar as this type of medical intervention eventually results in patients' death. Consequently, this fear has contributed to the tendency of doctors to over-treat patients in end-of-life stages. In previous court cases about treatment decisions that have directly impacted patients' lives, rulings have shown that patients' expressed intentions before he or she became incompetent must be verified and that patients must be in an irreversible death stage(12). Legal rulings have emphasized that the judgment of patients' conditions must be made in the most cautious manner possible. In other words, the right to make a judgment on a patient's condition has not been ceded to medical professionals, and instead remained in the hands of judicial authorities (25) prior to the legislation of the Act.

Such a conservative stance by the government is still reflected in the Act, thereby posing potential challenges to the practice of clinical ethics, even though the Act acknowledges the authority of medical professionals to judge whether a patient is in an irreversible state. It is worth our scrutiny that every article in the Act pertaining to decisions on life-sustaining treatment addresses the matter with regard to the specific period of time when a patient has entered the end-of-life process only. As previously mentioned, the end-of-life process, as defined by the law, refers to a stage much closer to the patient's coming death in comparison to the terminal stage of a patient's illness. Therefore, "end of life" is a significantly short span of time. Problems arise in that the Act specifies the duty of a healthcare institution ethics committee to provide guidance in determination of life-sustaining treatment, particularly life-sustaining treatment at patients' end of life, thereby limiting the scope of activities by ethics committees. While it is true that each individual ethics committee may take measures to autonomously extend their sphere of duties, the majority of medical institutions are likely to fail to take such a proactive approach, implementing only the bare minimum required by the law. Nevertheless, numerous ethical issues 
can arise in patient care before patients reach their end-of-life stages. For instance, if a patient diagnosed with a terminal illness were to ask a doctor to withhold life-sustaining treatment, several questions would arise: should the doctor refuse to withhold the patient's life-sustaining treatment? What kind of communication should the doctor initiate and with whom among the parties concerned, including patients and patients' relatives? What ethical and legal issues need to be considered? These are all highly nuanced questions, the proper addressing of which requires the practice of clinical ethics to help all the involved medical professionals together with patients and their families. However, insofar as the Act stipulates that ethics committees deal with ethical issues arising at patients' end of life only, the law may fail to facilitate discussions under such circumstances. What is more, the law effectively prevents these discussions from taking place unless the patient has entered the timeframe specified by the Act.

\section{(3) Medical professionals}

Regarding the authority of medical professionals, the Act stands to incite a delicate situation in terms of power dynamics. Medical professionals in Korea have assumed authority, just as Western medical professionals have, which has led to the rise of medical paternalism in Korea. As in other countries, the assumed authority of doctors is executed under close coordination with other authorities, which, in the case of Korea, are family and government. In other words, medical professionals use their power to decide upon patient treatments within the boundaries permitted by the government and patients' families. Regrettably, patients are often excluded from decision-making processes about their own treatments. On the other hand, implementation of the Act has resulted in some restriction of the authority and freedom of medical professionals, which was heretofore unfettered on the matter of treatment decisions. Previously, treatment could be withheld or withdrawn with the consent of a patient's family (or even a few family members), but now such practices have become impossible due to certain legal requirements around withholding life-sustaining treatment for patients.
In this context, does implementation of the Act compel medical professionals to realize their limited authority and recognize the need for clinical ethics practice? In other words, going forward, will doctors be inclined to turn to help from ethics committees or ethics consultants if they are required to make certain decisions on treatments? Taking into account the extent to which doctors believe that they were properly addressing similar issues before the Act based on their professional discernment, this might not be the case. As discussed above, the scope of legally prescribed activities for healthcare institution ethics committees is very limited. Not only that, matters related to the determination of life-sustaining treatment are stipulated in detail by the law, with requirement that expectations are met or otherwise punishable, so as to avoid further discussion or deliberation that may lead to the making of nuanced ethical judgment about patients' lives. Under these conditions, unless an individual medical professional is keenly interested in developing treatment plans that best serve a patient's interest-thereby requesting the help of a committee out of good will - there are not likely to be many cases where clinical medical professionals ask for help. Ultimately, medical professionals willing to advocate for patients are what a system of clinical ethics is looking to foster, and it is these medical professionals that any form of clinical ethics practice aims to support. The fact must be considered, however, that many medical professionals, at least during the nascent stages of clinical ethics practice, might not agree with the effectiveness and need for the practice of clinical ethics. From this standpoint it is clear that any form of clinical ethics practice needs to endeavor consistently and cleverly to overcome such obstacles.

\section{Conclusion}

Family, government, and medical professionals have the potential to pose realistic difficulties in successful implementation of the practice of clinical ethics. This is because the practice of clinical ethics will challenge the established roles and authority of these three agents in Korea's traditional social paradigm. However, there is no need for healthcare systems and patients to hopelessly accept the status quo. Implementation of the Act on Decisions on Life-Sustaining Treatment for 
Patients in Hospice and Palliative Care or at the End of Life in Korea has brought clear changes to the present situation. People are becoming increasingly aware of their rights to self-determination at the end of life. More people are looking for different types of end-of-life care to better align with their systems of values, and are actively asking to realize these alternative options. Facili- tated by the new law, these changes will eventually drive the practice of clinical ethics to flourish in Korea. Nevertheless, because such success will only be possible by way of conflict and resolution within the current social order, a keen recognition of the existing challenges and opportunities is necessary for advancement going forward.

\section{References}

1. The Act on Decisions on Life-Sustaining Treatment for Patients in Hospice and Palliative Care or at the End of Life. (Act No. 14013). Available from: URL: http://www.law.go.kr/engLsSc.do?tabMenuId=tab45\&query=\%EC\%9E\%84 \%EC\%A2\%85\%EA\%B3\%BC\%EC\%A0\%95\# [cited 2019 May 14].

2. Singer PA, Pellegrino ED, Siegler M. Clinical ethics revisited. BMC Medical Ethics 2001; 2(1).

3. Maeng KH. The Need for teaching ethics to medical students. Korean Journal of Medical Education 1990; 2 (2) 67-70.

4. The Korean Society for Medical Ethics. Available from: URL: https://medicalethics.jams.or.kr/co/main/jmMain.kci [cited 2019 May 14].

5. The Korean Bioethics Association. Available from: URL: http://koreabioethics.kr/sobis/bioethics.jsp [cited 2019 May $14]$.

6. Korean National Institute for Bioethics Policy. Available from: URL: https://www.nibp.kr:5002/xe/ [cited 2019 May 14].

7. Bioethics and Safety Act (Act No. 14013). Available from: URL: http://www.law.go.kr/lsSc.do?tabMenuId=tab18\&query $=\%$ EC $\% 83 \% 9 D \% E B \% A A \% 85 \% E C \% 9 C \% A 4 \% E B \% A 6 \% A C \#$ undefined [cited 2019 May 14].

8. The National Bioethics Committee. Available from: URL: https://bioethics.go.kr/user [cited 2019 May 14].

9. The Bioethics Policy Research Center. Current status of hospital ethics committee in 2011. Seoul: The Bioethics Policy Research Center; 2011.

10. Supreme Court of Korea. Sentence 92Da25885. Available from: URL: http://www.law.go.kr/LSW//precInfoP. do?precSeq=110075 [cited 2019 May 14].

11. Supreme Court of Korea. Sentence 2015Da13843. Available from: URL: http://www.law.go.kr/precSc.do?tabMenuId=tab67\&query=2015\%EB\%8B\%A413843\#licPrec179848 [cited 2019 May 14].

12. Supreme Court of Korea. Sentence 2009Da17417. Available from: URL: http://www.law. go.kr/\%ED\%8C\%90\%EB\%A1\%80/(2009\%EB\%8B\%A417417) [cited 2019 May 14].

13. National Agency for Management of Life-Sustaining Treatment. Available from: URL: https://lst.go.kr/main/main.do [cited 2019 May 14].

14. American Society for Bioethics and Humanity HECE certification commission. Healthcare Ethics Consultant-Certified Program. Available from: URL: http://asbh.org/certification/hcec-certification [cited 2019 May 14].

15. Patient Self Determination Act. H.R.4449. Available from: URL: https://www.congress.gov/bill/101st-congress/housebill/4449 [cited 2019 May 14].

16. Joint Commission on Accreditation of Healthcare Organizations. Accreditation manual for hospitals. Oakbrook Terrace: JCAHO; 1992.

17. Jonsen AR. A short history of medical ethics. New York: Oxford University Press; 2000.

18. Tsai DFC. Personhood and autonomy in multicultural health care settings. AMA Journal of Ethics 2008; 10(3): 171176.

19. Chan HM. Sharing death and dying: advance directives, autonomy and the family. Bioethics 2004; 18(2): 87-103.

20. Fan R. Self-determination vs. family-determination: two incommensurable principles of autonomy. Bioethics 1997; 11(3-4); 309-322.

21. Kwon I, Koh Y, Yun YH et al. A study of the attitudes of patients, family members, and physicians toward the withdrawal of medical treatment for terminal patients in Korea. Korean Journal of Medical Ethics 2010; 13(1): 1-16.

22. Buchanan AE, Brock DW. Deciding for Others; the ethics of surrogate decision making. New York: Cambridge University Press; 1990: 87-151. 
Challenges and Opportunities in Clinical Ethics with the Implementation of Korea's End-of-Life Act - Claire Junga Kim

23. Nancy B, Bruce J, Susan M W. The Hastings Center guidelines for decisions on life-sustaining treatment and care near the end of life. revised and expanded $2^{\text {nd }}$. ed. New York: Oxford University Press; 2013: 43-66.

24. Criminal Law. (Act No. 14415). Available from: URL: http://www.law.go.kr/engLsSc.do?tabMenuId=tab45\&query $=\%$ ED $\% 98 \% 95 \%$ EB\%B2\%95\# [cited 2019 May 14].

25. Kim NK, Harmon SHE. Acceptance, Modification and Rejection of Paternalism in Korean Medical Law. Development and Reproduction 2010;14(2): 143-154.

Received: May 24, 2019

Accepted: June 29, 2019 